Unsere Experten beraten Sie bei kniffeligen medizinischen Fragestellungen aus Ihrer Praxis.
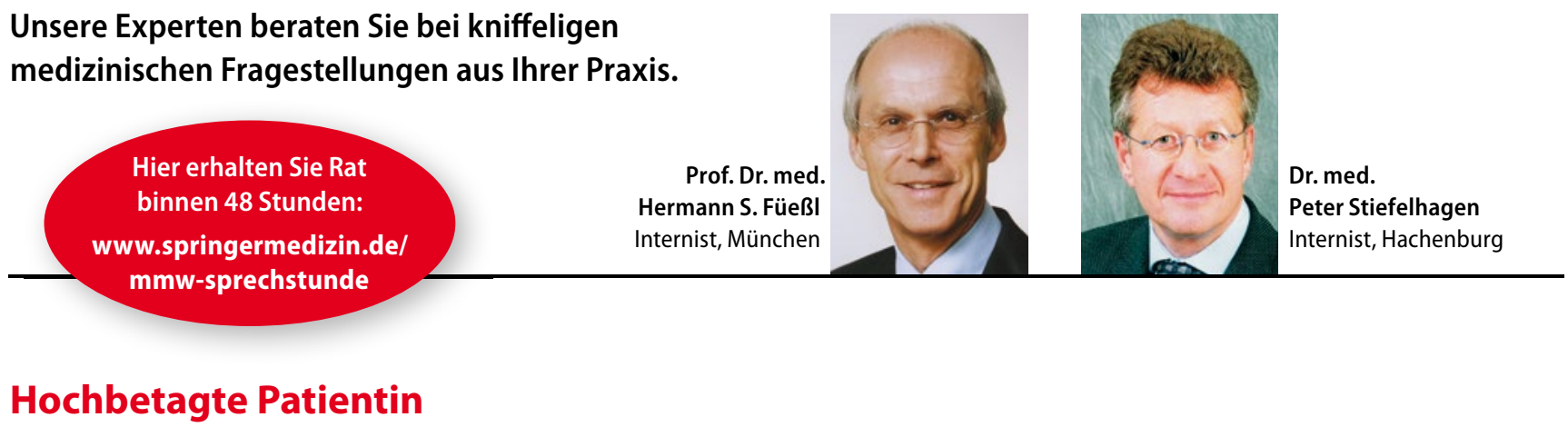

\title{
Was ist die Ursache des Perikardergusses?
}

1 Frage von Dr. S. S.: Eine über 90-jährige, relativ fitte, selbstständig mit ihrem Mann lebende Patientin, bei der seit 2009 ein 0,5-1 cm breiter Perikarderguss bekannt ist, stellte sich nach einem Klinikaufenthalt neu bei mir vor. Der Kardiologe hatte sie wegen thorakaler Schmerzen, Verschlechterung einer chronischen Dyspnoe und zunehmendem Husten mit Auswurf eingewiesen. Man fand einen $4 \mathrm{~cm}$ breiten, überwiegend links lokalisierten Perikarderguss, zudem einen basalen Pleuraerguss, links mehr als rechts. Außerdem wurden eine Pneumonie links basal und ein Harnwegsinfekt festgestellt, die antibiotisch behandelt wurden.

Es konnte kein Anzeichen für eine paraneoplastische Genese des Perikardergusses gefunden werden. Die Punktion ergab $750 \mathrm{ml}$ eines stark hämorrhagisch tingierten Ergusses, der sich histologisch tumorzellfrei mit Bestandteilen peripheren Bluts und leichter Vermehrung neutrophiler Granulozyten zeigte.

Aus der Vorgeschichte sind zwei Myokardinfarkte 2001 und 2006 sowie ein Nicht-ST-Hebungs-Myokardinfarkt ohne Intervention im Rahmen einer Magenwandresektion wegen einer Blutung aus einem Magenlipom 2009 bekannt. Wegen eines klarzelligen Nierenzellkarzinoms erfolgte eine Teilresektion beider Nieren. 2012 kam es

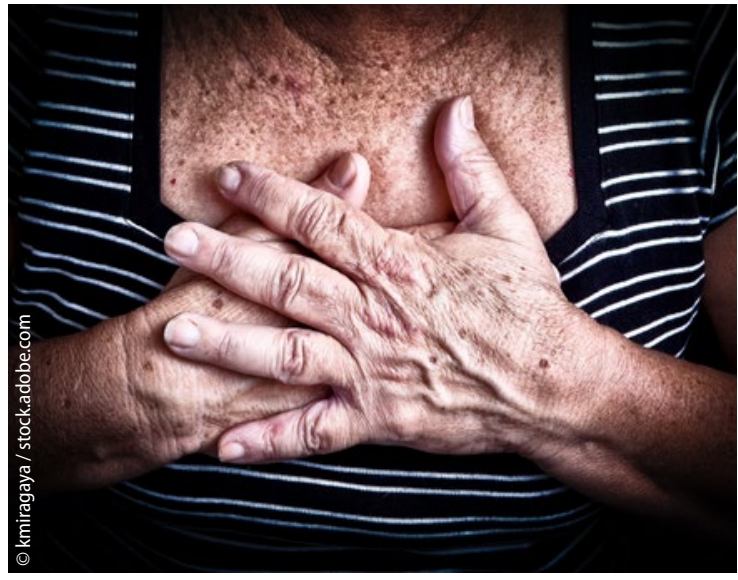

Die Patientin kam mit Thoraxschmerzen in die Klinik. zu einem Rezidiv mit Bestrahlung, ein Tumor-Staging 2015 ergab einen stabilen Befund.

Die Patientin spritzt 14 IE Insulin basal abends und zusätzlich je nach Blutzuckerwert Insulin glulisin. Blutdruckmessungen bei uns ergaben 138/64 und 135/75 $\mathrm{mmHg}$.

Die Medikation der Patientin umfasst außerdem Lercanidipin, Metoprolol, Ramipril, Isosorbiddinitrat, Molsidomin, Torasemid, Simvastatin, ASS, L-Thyroxin, Omeprazol, Xipamid, Kalziumacetat und Macrogol.

Was könnte die Ursache des Perikardergusses gewesen sein? Womöglich sogar eines der Medikamente? MMW-Experte Stiefelhagen: Bei der Tumoranamnese muss in erster Linie an eine maligne Ursache im Sinne einer Perikardkarzinose gedacht werden, auch wenn das zytologisch nicht gesi- chert werden konnte. Als weitere Ursache sollte auch eine Aortendissektion diskutiert werden. Eine medikamentöse Ursache ist höchst unwahrscheinlich. Für die genannten Substanzen ist so etwas nicht bekannt.

I MMW-Experte FüeßI: Trotz des fehlenden Nachweises von Tumorzellen in der Perikardflüssigkeit kommt bei der Vorgeschichte der 90-jährigen $\mathrm{Pa}$ tientin eine maligne Erkrankung als Ursache für den hämorrhagischen Perikarderguss in Betracht. Es erhebt sich die Frage, welche Menge abpunktiert wurde und wie das Punktat untersucht wurde. Falls der Erguss weitgehend abpunktiert wurde und in kurzer Zeit wieder nachgelaufen ist, so wäre das ein Indiz für diese Hypothese.

Da bereits seit mehreren Jahren ein kleiner Perikarderguss bestanden und dieser rasch zugenommen hatte, käme auch eine Verschlechterung der linksventrikulären Pumpfunktion durch Auftreten eines ansonsten asymptomatischen epikardnahen Myokardinfarkts als Ursache infrage.

\section{Und wie geht es weiter?}

Nimmt diese Patientin zu viele Medikamente ein? Lesen Sie die Einschätzung unserer Experten in der nächsten MMW! 